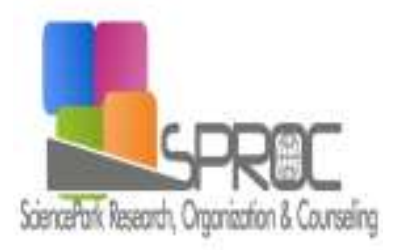

\section{New Trends and Issues Proceedings on Humanities and Social Sciences}

Volume 4, Issue 1 (2017) 291-296
'New Trends and Issues Proceedings on Humanities and Social Sciences

ISSN 2421-8030

www.prosoc.eu

Selected Papers of 9th World Conference on Educational Sciences (WCES-2017) 01-04 February 2017 Hotel Aston La Scala

Convention Center, Nice, France

\title{
Technical translation teaching and learning at initiation level: Methodological considerations
}

Mirela Cristina Pop ${ }^{a^{*}}$, Department of Communication and Languages, Faculty of Communication Sciences, Politehnica University of Timisoara, 2A Traian Lalescu Str., 300223, Timisoara, Romania.

\section{Suggested Citation:}

Pop, C. M. (2017). Technical translation teaching and learning at initiation level: Methodological considerations. New Trends and Issues Proceedings on Humanities and Social Sciences. [Online]. 4(1), pp 291-296. Available from: www.prosoc.eu

Selection and peer review under responsibility of Prof. Dr. Jesus Garcia Laborda, University of Alcala, Spain. ${ }^{\circ} 2017$ SciencePark Research, Organization \& Counseling. All rights reserved.

\begin{abstract}
This paper presents some methodological aspects that can be used to describe the teaching and learning process of technical translation at initiation level in higher education starting from the modular approach that we have outlined in previous research. The approach is derived from the pedagogical principles of the competence-based approach that conceives the teaching and learning process in terms of competence-based training. The approach adopted could, in our opinion, target the following aspects: defining training objectives, structuring curricular content, describing pedagogical strategy and elaborating teaching resources. The proposed methodological model also relies on the experience of teaching French to engineering students and general and technical translation from French to Romanian in academic field, as well as on observing professional practices.
\end{abstract}

Keywords: Technical translation teaching and learning; technical translators training; initiation level; modular approach; competence-based approach.

\footnotetext{
* ADDRESS FOR CORRESPONDENCE: Mirela Cristina Pop, Department of Communication and Languages, Faculty of Communication Sciences, Politehnica University of Timisoara, 2A Traian Lalescu Str., 300223, Timisoara, Romania.

E-mail address: mirela.pop@upt.ro / Tel.: +00 40256404012
} 
Pop, C. M. (2017). Technical translation teaching and learning at initiation level: Methodological considerations. New Trends and Issues Proceedings on Humanities and Social Sciences. [Online]. 4(1), pp 291-296. Available from: www.prosoc.eu

\section{Introduction}

Technical translation is a representative category in the translation market and occupies a large place in the curriculum of study programs at bachelor's and master's degree of translation schools from around the world. The pedagogical and methodological approaches of technical translation highlight the particularities of this type of translation training in different language combinations: the training and autodidactic approaches for technical translators, the tools for technical translators and the translation-oriented terminology activities (Wright \& Wright, 1993); the training of technical translators based on typical difficulties encountered in technical translation (Baumgartner, 1993); the analysis of the technical texts in terms of 'metathemes' (Izarenkov \& Oleinik, 1996); the successive phases of technical translation training (Marquant, 2005); the distinction between the objectives of technical translator training and technical translation teaching to engineering students (professional objectives vs. communicational objective, Pop, 2010); the technical translation teaching to the engineering students based on the authentic technical documents (Tarasova, 2015); the role of motivation in technical translation teaching (Tarasova et al., 2015), etc.

In the field of the didactics of translation and languages, we sustain a modular approach aimed at teaching and learning translation and foreign languages by levels, from general to (more) particular, taking into consideration the pedagogical and methodological principles of the competence-based approach (Pop \& Tanase-Robescu, 2009, Pop \& Mazilescu, 2012, Pop, 2012; 2015).

According to the competence-based approach, a pedagogical movement that has led to the reform of university systems, the teaching and learning process is designed in terms of training (Pop \& Mazilescu, 2012: 4202): the training are defined as competences intended to be acquired by future graduates; the competences are formulated in terms of knowledge ('cognitive competences') or skills and know-how ('functional / action-oriented competences').

The competences formulated by experts form the basis for the development of study programs in various fields. The competences are outlined and described in relation to the requirements and expectations of the professional environment (Marquant, 2005).

This paper outlines a methodological approach that can be used to describe the teaching and learning process of technical translation at initiation level: defining training objectives, structuring curricular content, describing pedagogical strategy.

\section{Operational notions}

\subsection{The concept of technical translation}

The technical translation is generally defined as a sub-category of specialised translation, studied in opposition to general translation. Differences between the categories of translators and translations are based on three dimensions: the technicality of the materials to be translated, the specialities and the markets and the status of the translators (Gouadec, 2009).

The technical translation is distinguished from other types of specialised translations by its "technical contents" and "technical discourse" (Marquant, 2005). The content revises an area of specialisation that functions as an operational "delimiter" (Marquant, 2005). In the case of technical translation, the "technical content" refers to three aspects: "field (s) of human activity", exact / technical and technical sciences and general technology / applied technology / industrial interface". The "technical discourse" 
delimits itself in relation to other types of discourse (juridical, economic, scientific, etc.) by the "density" and the "extensibility" of the terminology used (Marquant, 2005).

According to Vigner and Martin (1976), the technical language presents certain characteristics which are supposed to differentiate it from common language: the almost total disappearance of the difference between written and oral discourse, the homogeneity of the language used, the impersonal dimension of communication, the effacement of the enunciation subject behind the object of its purpose, the timeless characteristic of the technical operations and the properties of materials, the objectivity of communication, the precision and conciseness of technical information.

\subsection{The concept of translation teaching and learning}

The paradigm shift in education has led to a renewal of the teaching and learning process which emphasizes the idea of the importance of a close relation between the curricular content and the professional environment.

Under the influence of the competence-based approach, the notion of teaching and learning is understood as training. The training is based on criteria that describe the competences and the minimum level of performance that a student must attain at the end of the training.

Concerning the translators training, the distinction between general and specialised translation leads to two possibilities for translation teaching and learning in higher education: a general and a specialised training.

The general training is acquired as part of bachelor's degree aimed at the acquisition by students of the translation competence of general texts, while training in specialised translation, including technical translation, is generally provided through master programs.

We can thus notice that the traditional notion of translation teaching and learning designating the content of the programs proposed by the schools of translation (Delisle, 1980) is replaced by the notion of translators training, which is defined as "translation task-based approach" (Hurtado-Albir, 2007).

\section{Technical Translators Training at Initiation Level: Some Methodological Aspects}

\subsection{Translation teaching and learning: A modular approach}

The application of the pedagogical and methodological principles of the competence-based approach have led us to consider a "modular approach" to translation teaching and learning at university level with three stages (Pop, 2015): a stage of initial training, a stage of specialised translation at initiation level and a stage of specialised translation at professional level. At each stage there are specific training objectives, curricular content and appropriate teaching and learning methods.

The foundations of a teaching and learning approach to general translation are outlined in the second part of a book that explores the "theoretical, practical and didactic aspects" of general translation from French to Romanian in higher education (Pop, 2013).

By analogy, a teaching and learning approach to specialised translation, at initiation or professional level, could focus, in our view, on the following aspects: defining training objectives, structuring curricular contents, identifying translation problems, describing pedagogical strategy and elaborating teaching resources.

We consider that any specialised training should be preceded by an initiation phase with specific training objectives (Pop, 2015). In our opinion, the difference between the stages of specialised training at general and professional level is based on the following aspects: the degree of "technicality" of the 
Pop, C. M. (2017). Technical translation teaching and learning at initiation level: Methodological considerations. New Trends and Issues Proceedings on Humanities and Social Sciences. [Online]. 4(1), pp 291-296. Available from: www.prosoc.eu

materials to be translated, identifiable according to the criteria of "density" and "extensibility" of the terminology mentioned above; the recipient of the translation, specialist or not in a particular domain.

\subsection{Training objectives}

Training objectives are generally defined in relation with the professional environment in the country where training is provided. Taking into consideration the competence-based approach, as mentioned above, the objectives are set out in terms of competences with two components: knowledge (cognitive competences) and know-how (functional / action-oriented competences).

Knowledge, in technical translator training at initiation level, is closely connected to the acquisition of the epistemological basis in the technical field: knowledge and use of the specific notions of the general technical field; the understanding of technical culture, which refers to processes, operations and products in the technical field.

This category of knowledge is generally provided in the mother tongue by a professional who must adapt the content and discourse to the objectives of the training. The discipline which corresponds to this objective is generally aimed at acquiring the fundamental notions of science and technology in mother tongue. The specific knowledge of terminology and technical language, through the acquisition of technical vocabulary in two foreign languages are also part of the cognitive competences to be acquired by students, being considered related disciplines such as Terminology or Languages for Specific Purposes.

The know-how refers to the acquisition by students of the translation skills, generally from a foreign language to the mother tongue, in most formations, or in both directions, in certain study programs: analysis for the understanding of technical texts of general interest; information and documentation (terminological, thematic, encyclopaedic research); identification and solution of translation problems of technical texts; application of translation techniques specific to technical translation; application of the criteria for the assessment of the translation.

\subsection{Structuring curricular content}

Content structuring responds to a pedagogical purpose: to ensure the progression of competences. Concerning the technical translators training at initiation level, the structuring of the curricular content aims at identifying the problems to be dealt with. Let us present some problems identified during the technical translation classroom from French to Romanian:

-The understanding of technical texts: the identification of the domain, theme and subject (e.g. robots humanoïdes / roboți umanoizi "humanoid robots / human-shaped robot / human-sized robots"; the identification of technical terms, terminological collocations and phraseology (e.g. roboticien / specialist în robotica "robotician"; robots humanoïdes secouristes / roboți umanoizi specializați în misiuni de salvare "rescue robots"); the identification and analysis of culture-specific items relating to realities arising from foreign technical culture (e.g. Allistene "Alliance of Digital Science and Technology"); the use of tools (dictionaries, glossaries, databases, advanced search techniques, electronic and multimedia resources, as visual technical dictionaries, parallel documents in the field of text to be translated); the use of experts and the credibility of the resources consulted;

-The translation of technical text: the identification of translation problems, particularly of terminological problems, due in particular to the construction of terms: derivation (e.g. humanoïde / umanoid "humanoid"); composition (e.g. nano-robots / nanoroboți "nano-robots"); abbreviation (VUS vehicule utilitaire sport / SUV - vehicul sportiv-utilitar "SUV - sport utility vehicle or suburban utility vehicle"); borrowing, usually from English, especially in the digital field (e.g. open source, big data, etc.); the "extensibility" of the terminology used (e.g. centrale inertielle ou centrale à inertie / unitați de 
masurare inerțiala (IMU) "IMU - inertial measurement unit - instrument used in navigation to estimate the orientation of a moving object, its linear velocity and its position"); the application of interlinguistic and intercultural techniques specific to technical translation; functional specialisation of certain terms;

-The assessment and self-assessment in technical translation, from the perspective of the student: reflection on the translating process carried out, difficulties encountered, experience gained during translation, improve the quality of its own translation, etc.

\subsection{Describing pedagogical strategy}

The pedagogical strategy implies the design of the pedagogical scenario: selection of methods and activities, formulation of the tasks to be fulfilled by the students, selection of the materials to be translated, etc.

In our opinion, the application methods are appropriate for technical translation teaching and learning at initiation level. These methods emphasize the learning process and are specific to practical or guided tasks: demonstrations, presentation of tools, exercises based on case studies, research.

The selection of activities is carried out according to the constraints linked to the training system and the objectives pursued by the teacher for each unit. Activities can be organised around a translation problem, a learning objective or a translation task.

Marquant (2005) identifies six successive phases of technical translators training: preparatory exercises, simulation exercises, pedagogical workshops, certification, work placement and employment. The first three phases can characterize the teaching and learning technical translation at initiation level. The teacher can focus on activities meant to activate the progression of students competences: identification and use of tools, transcoding activities, reformulation activities, technical writing in source and target language, etc. The translation project can be a professional simulation exercise useful in technical translation classroom at initiation level, a method meant to lead to the students autonomy.

The selection of materials to be translated must also be done in connection with the training objectives previously established: to familiarize students with technical translation. The materials can be selected from general technical information publications that take stock of innovations in cuttingedge fields of technology (e.g. robotics, computer science, construction, mechanical engineering).

\section{Conclusion}

The methodological approach outlined above can be used to describe the process of teaching and learning translation in academic field, at bachelor's and master's degree, for three different stages of the technical translators training: general training, specialised training at general level and specialised training at professional level.

The application of the principles of the competence-based approach has enabled us to identify the main dimensions of a possible methodological approach to technical translation teaching and learning at initiation level: defining training objectives, structuring curricular content and describing pedagogical strategy.

This type of training also has a professional objective as it connects training to professional environment. The training objectives can be described in relation with the competences needs of the 
Pop, C. M. (2017). Technical translation teaching and learning at initiation level: Methodological considerations. New Trends and Issues Proceedings on Humanities and Social Sciences. [Online]. 4(1), pp 291-296. Available from: www.prosoc.eu

professional environment in which the training is provided and with the particularities of the teaching and learning situation specific at university at bachelor's or master's degree.

\section{References}

Baumgartner, P. (1993). Technical translation: Putting the right terms in the right context. In C. Dolerup \& A. Lindegaard (Eds.), Teaching Translation and Interpreting 2. Insights, Aims, Visions (pp. 295-300). Amsterdam/Philadelphia: John Benjamins Publishing Company.

Delisle, J. (1980). L'analyse du discours comme methode de traduction. Ottawa: Editions de l'Universite d'Ottawa. Gouadec, D. (2009). Profession traducteur. (2nd ed.). Paris: La Maison du Dictionnaire.

Hurtado-Albir, A. (2007). Competence-based curriculum design for training translators. The Interpreter and Translator Trainer, 1(2), 163-195.

Izarenkov, D. I. \& Oleinik, O. (1996). Selecting texts for teaching technical translation. Perspectives, 4(2), 203-213. Marquant, H. (2005). Formation à la traduction technique. Meta: Translators' Journal, 50, 129-136.

Pop, M. \& Tanase R. D. (2009). Towards a new curricular design for foreign language teaching in romanian technical universities, In C. Oprean \& N. Grünwald, \& C.V. Kifor (Eds.), Balkan Region Conference on Engineering and Business Education \& International Conference on Engineering and Business Education, II, (pp. 326-329). Sibiu: Lucian Blaga University of Sibiu.

Pop, M. (2012). De la competence de communication generale à la competence de communication en langue de specialite. In F. Valetopoulos \& Jolanta Zając (Eds.), Les competences en progression: Un defi pour la didactique des langues, (pp. 339-350). Varsovie: Universite de Varsovie \& Poitiers: Universite de Poitiers.

Pop, M. C. (2010). Foreign Language Teaching at Technical Universities: Written Mediation Activities. In B. Katalinic (Ed.), Annals of DAAAM for 2010 \& Proceedings of the 21th International DAAAM Symposium, 20, No1, (pp. 1519-1520). Vienna: DAAAM International.

Pop, M. C. (2013). La Traduction. Aspects theoriques, pratiques et didactiques. Timișoara: Orizonturi universitare.

Pop, M. C. \& Mazilescu, C. A. (2012). Competence based-curricula design in foreign language teaching in the Romanian technical universities. Procedia - Social and Behavioral Sciences, 46, 4200-4204.

Tarasova, E. S. (2015). Technical translation teaching to the engineering students (on the example of patent descriptions). Mediterranean Journal of Social Sciences, 6(3), 350-355.

Tarasova, E., Kradetskayaa, A. \& Kudlay, A. The role of motivation in technical translation teaching to master degree students. Procedia - Social and Behavioral Sciences, 206, 189-192.

Vigner, G. \& Martin, A. (1976). Le français technique. Paris: Hachette et Larousse.

Wright, S. E. \& Wright, L. D. J. (Eds.). (1993). Scientific and technical translation. Amsterdam/Philadelphia: John Benjamins Publishing Company. 